\title{
THEORETICAL STUDIES OF INTERSTELLAR ISOMERS
}

\author{
D. J. DeFrees \\ Molecular Research Institute \\ 701 Welch Road, Suite 203 \\ Palo Alto, CA 94304
}

\begin{abstract}
Both observational and theoretical studies of molecular cloud chemistry are hindered by many difficulties which are partially circumvented by studying the relative abundances of isomers synthesized from a common set of chemical precursors. Theoretical studies aimed at understanding interstellar abundance ratios for the isomers $\mathrm{HCN} / \mathrm{HNC}, \mathrm{HCO}^{+} / \mathrm{HOC}^{+}, \mathrm{CH}_{3} \mathrm{CN} / \mathrm{CH}_{3} \mathrm{NC}$, and $\mathrm{C}_{3} \mathrm{H}_{2}$ have been performed.
\end{abstract}

Chemically related isomers, molecules with the same stoichiometry and which derive from common chemical precursors, can be studied to increase understanding of gas phase molecular cloud chemistry. Many of the uncertainties associated with observational, experimental, and theoretical investigations of interstellar chemistry can be minimized by examining isomer abundance ratios rather than absolute abundances for single species. Theoretical methods have been used to examine a number of isomer pairs. In general, a very accurate level of $a b$ initio molecular orbital theory is used to quantitatively define a potential energy surface. The surface is used in molecular dynamics calculations, of ten employing phase space theory, to determine chemical reaction rates. These, when combined with estimates for the abundances of the chemical starting materials, lead to the desired abundance ratios. The abundance ratios so computed should be accurate to better than an order of magnitude.

The only confirmed pair of chemically-related, interstellar isomers is hydrogen cyanide (HCN)/hydrogen isocyanide (HNC). The interstellar abundance of HNC relative to $\mathrm{HCN}$ is greatly enhanced in comparison to the equilibrium value. Furthermore, the ratio varies from source to source - HCN:HNC is as small as 2:3, in TMC-1, and as large as 20:1, in Orion. The essential reason that the ratio is near unity is that the isomers are produced equally from the dissociative recombination of $\mathrm{HCNH}^{+}$ with electrons. However, it has been suggested that the isomer $\mathrm{H}_{2} \mathrm{CN}^{+}$can lead to $\mathrm{HCN}$ only while $\mathrm{H}_{2} \mathrm{NC}^{+}$leads exclusively to $\mathrm{HNC}$. Theoretical calculation argue against this scenario as both of these isomers can rearrange to the linear $\mathrm{HCNH}^{+}$species. $\mathrm{H}_{2} \mathrm{CN}^{+}$ rearranges without activation (DeFrees and McLean 1985a) while $\mathrm{H}_{2} \mathrm{NC}^{+}$rearranges over a barrier which is lower in energy than its precursors. (DeFrees, Binkley, Frisch, and McLean 1985.) 
The formyl ion, $\mathrm{HCO}^{+}$, is well known and widely distributed through the galaxy. Its isoformyl isomer, $\mathrm{HOC}^{+}$, has been tentatively identified in Sgr B2 based upon the detection of the $\mathrm{J}=1 \rightarrow 0$ line. Theoretical and experimental studies, however, indicate, that the reaction $\mathrm{HOC}^{+}+\mathrm{H}_{2} \rightarrow \mathrm{HCO}^{+}+\mathrm{H}_{2}$ can proceed at an appreciable rate under dense cloud conditions. (Jarrold et al. 1985.) This suggests that the detection of HOC+ in Sgr B2 can only be correct if the chemical model is inaccurate, the cloud is lumpy (containing imbedded diffuse regions), or their are diffuse cloud regions along the line of sight to Sgr B2.

Methyl cyanide, $\mathrm{CH}_{3} \mathrm{CN}$, is observed in several sources and is believed to be formed when methyl cation, $\mathrm{CH}_{3}^{+}$, combines radiatively with $\mathrm{HNC}$ to form $\mathrm{CH}_{3} \mathrm{CNH}^{+}$which subsequently recombines with an electron to give $\mathrm{CH}_{3} \mathrm{CN}$. Methyl isocyanide, $\mathrm{CH}_{3} \mathrm{NC}$, would reasonably be expected to form when $\mathrm{CH}_{3}^{+}$reacts with $\mathrm{HCN}$, however efforts to detect it have led only to an upper limit in TMC-1 which place it at $<9 \%$ of the $\mathrm{CH}_{3} \mathrm{CN}$ abundance. Molecular orbital theory shows that there is a pathway connecting the two intermediate ions, $\mathrm{CH}_{3} \mathrm{CNH}^{+}$and $\mathrm{CH}_{3} \mathrm{NCH}^{+}$, such that they can interconvert when $\mathrm{CH}_{3}^{+}$reacts with $\mathrm{HCN}$. Thus, both isomers are produced by this reaction. (Reaction of $\mathrm{CH}_{3}^{+}$with $\mathrm{HNC}$ leads primarily to $\mathrm{HCN}$ and $\mathrm{CH}_{3}^{+}$.) Phase space calculations estimate that the ratio of product ions, and presumably thus the product neutrals, is in the range $\mathrm{CH}_{3} \mathrm{NC}: \mathrm{CH}_{3} \mathrm{CN} \simeq 0.1$ to 0.4 . This is thus consistent with the TMC-1 observation and it suggests that $\mathrm{CH}_{3} \mathrm{NC}$ should be more abundant than has been observed to date. (DeFrees, McLean, and Herbst 1985.)

The most stable $\mathrm{C}_{3} \mathrm{H}_{2}$ isomer is the cyclic species cyclopropenylidene which recently became the first cyclic organic molecule to be detected in space. (Thaddeus, Vrtilek, and Gottlieb 1985.) In the detection paper it was suggested that an acyclic $\mathrm{C}_{3} \mathrm{H}_{2}$ isomer, propargylene, $\mathrm{HCCCH}$, was also present and three harmonically related lines were proposed to be due to its presence. Molecular orbital calculations fail to support this hypothesis as the predicted rotational constants for both the triplet and the singlet propargylene isomers are $2 \%$ higher than the proposed astronomical frequencies and the level of theory used is usually accurate to $\pm 1 \%$.

\section{REFERENCES}

DeFrees, D. J. and McLean, A. D. 1985a, 'Does carbon-protonated hydrogen cyanide, $\mathrm{H}_{2} \mathrm{CN}+$, exist?', J. Amer. Chem. Soc., 107, 4350.

DeFrees, D. J. and McLean, A. D 1985b, 'A b initio molecular orbital studies of low-energy, metastable isomers of the ubiquitous cyclopropenylidene', $A p . J$. (Letters), submitted.

DeFrees, D. J., Binkley, J. S., Frisch, M. F., and McLean, A. D. 1985, 'The lowest singlet and triplet potential energy surfaces of the astrophysically important ion $\mathrm{CH}_{2} \mathrm{~N}^{+}$, $J$. Chem. Phys, manuscript in preparation.

DeFrees, D. J., McLean, A. D., and Herbst, E. 1985, 'Theoretical investigation of the interstellar $\mathrm{CH}_{3} \mathrm{NC} / \mathrm{CH}_{3} \mathrm{CN}$ ratio', $A p$. J., 293, 236.

Jarrold, M. F., Bowers, M. J, DeFrees, D. J., McLean, A. D., and Herbst, E. 1985, 'A reanalysis of the $\mathrm{HCO}^{+} / \mathrm{HOC}^{+}$abundance ratio in dense interstellar clouds', $A p$. $J$., in press.

Thaddeus, P., Vrtilek, J. M., and Gottlieb, C. A. 1985, 'Laboratory and astronomical identification of cyclopropenylidene, $\mathrm{C}_{3} \mathrm{H}_{2}{ }^{\prime}, A p$. $J$. (Letters), in press. 